
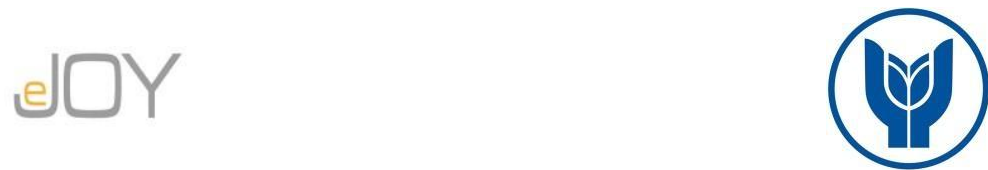

Sarı Gök, H., Aylan, F. K., Şalvarc1, S. / Journal of Yasar University, 2021, 16/62, 698-717

\title{
Yalnız Seyahat Eden Turistlerin Seyahat Motivasyonu ve Deneyimi: Z Kuşağı Örneği
}

\section{Travel Motivation and Experience of Solo Tourists: Z Generation Example}

\author{
Hatice SARI GÖK, Isparta Uygulamalı Bilimler Üniversitesi, Türkiye, haticesarigok@isparta.edu.tr
}

Orcid No: 0000-0003-0949-2593

Fatmanur Kübra AYLAN, Selçuk Üniversitesi, Türkiye, kubraceliloglu@gmail.com

Orcid No: 0000-0002-6703-2934

Simge ŞALVARCI, Selçuk Üniversitesi, Türkiye, simge_tokay@hotmail.com

Orcid No: 0000-0003-0703-4126

\begin{abstract}
Öz: Dünya çapında ulaşım ve bilişim teknolojilerindeki gelişmeler birçok sektörle birlikte turizm sektörünü de etkilemiştir. Bu gelişmeler turistlere kendi turlarını organize edebilme imkânı vermekle birlikte tur esnasinda kullanma açısından da çeşitli avantajlar sağlamaktadır. Bu avantajlar sayesinde bireyler tatillerini tek başııa planlamakta ve yalnız seyahat etmektedir. Yalnız seyahat kavramı, yalnız bir kişi tarafindan yapılan seyahatleri kapsamaktadır. Yalnız seyahat eden turistler, son yıllarda büyük bir ilerleme kaydederek gelişmekte olan ülkeleri ziyaret etme, macera, rahatlama ve yeni kişiler tanıma eğilimindedirler. Bununla birlikte, kişisel gelişim ve benzersiz deneyimler, yalnız seyahat kavramının önemli yönlerini oluşturmaktadir. Turistler yalnız seyahat edebildikleri gibi seyahatleri sirasinda bir gruba dâhil olabilmektedirler.

Bireyleri yalnız seyahat etmeye yönlendiren bazı içsel ve dı̧şal motivasyon kaynakları vardır. Bu seyahatler esnasında bireyler çeşitler deneyimler yaşamaktadır. Bu bağlamda, çalışmanın temel amacı Z kuşağında yer alan yalnız seyahat eden turistlerin seyahat motivasyonu ve deneyimini incelemektir. Çalışma nitel yöntem ile desenlenmiş olup yarı yapılandırılmış görüşsme tekniği kullanılmıştır. Araştırmanın örneklemini Z kuşă̆ında yalnız seyahat eden 10 turist oluşturmaktadır. Elde edilen görüşme verileri, MAXQDA 2018 programinda analiz edilmiştir. Bulgulara göre, Z kuşağı turistleri yalnız seyahate çıkma motivasyonlarını; yeni yerler görme, yeni insanlarla tanışma, macera arayışı, özgürlük hissi, öğrenme olarak belirtmişlerdir. Bununla birlikte yalnız seyahat ettiği için kendilerine güveninin arttı̆̆ın ve yalnı gerçekleştirdikleri seyahatlerinde çoğunlukla olumlu deneyim yaşadıklarını belirtmişlerdir.
\end{abstract}

Anahtar Kelimeler: Yalnı Seyahat Hareketi, Yalnız Seyahat Eden Turist, Z Kuşağl, Seyahat Motivasyonu ve Deneyimi

JEL Siniflandirmasl: L83, Z30, Z31

Abstract: Developments in transportation and information technologies across worldwide have affected the tourism sector along with many other sectors. These developments provide tourists with the opportunity to organize their own tours, but also provide various advantages in terms to be used during the tour. Thanks to these advantages, individuals plan their vacations and travel alone. The concept of traveling alone includes travels made by only one person. Tourists traveling alone tend to make great progress in recent years, visit developing countries, adventure, relaxation and meet new people. However, personal development and unique experiences are important aspects of the concept of traveling alone. Tourists can travel alone as well as belonging to a group during their travels.

There are some sources of intrinsic and extrinsic motivation that lead individuals to travel alone. During these trips, individuals experience various kinds of experiences. In this context, the main purpose of the study is to examine generation $Z$ tourists' motivation and experience on the travel who travel alone. The study was designed with qualitative method and semi-structured interview technique was used. The sample of the research consists of 10 tourists in Generation Z traveling alone. The interview data was analyzed in the MAXQDA 2018 program. According to the findings, generation $Z$ tourists determined their motivation to travel alone. They stated their motivations as seeing new places, meeting new people, seeking adventure, feeling of freedom, learning. However, they stated that thanks to traveling alone, their self-confidence increased and they mostly had positive experiences in their solo travels. 
Keywords: Solo Travel Movement, Solo Travel Tourist, Z Generation, Travel Motivation and Experience JEL Classification: L83, Z30, Z31

\section{Giriş}

Hızla büyüyen ulusal ve uluslararası turizm pazarında pazar bölümleri değişkenlik göstermektedir. Pazar bölümleri arasında yalnız seyahat eden turistler bu büyüyen turizm pazarının önemli bir parçası haline gelmiştir. Bilişim ve iletişim teknolojilerindeki gelişmelerin yanı sıra yaşam tarzı ve sosyal yapılardaki değişiklikler yalnız seyahat eden turist sayısını arttırmıştır (Jordan ve Gibson, 2005; Brown ve Osman, 2017). Visa Global Travel Intention tarafından yapılan araştırmaya göre (Brown, 2015), beş kişiden biri yalnız seyahat etmektedir (Osman, Brown ve Phung, 2020: 248). Klook’un (2019) 2400 katılımcı üzerine yaptığı seyahat trendleri araştırması, yalnız seyahatin tur ve etkinlik sektöründeki altı trendden birini temsil ettiğini ortaya koymaktadır. Ayrıca, paket turların sahip olduğu sınırlı özellikler ile destinasyon ve turizm aktivitelerine ilişkin bilgilerin daha hızlı ve kolay bir şekilde elde edilebilmesi, ulaşım alanında meydana gelen teknolojik gelişmeler, insanların seyahatlerinde özgür olma isteği, demografik yapıdaki değişim gibi faktörler, insanları kitle halindeki seyahatten bireysel seyahatlere doğru her geçen yıl daha fazla yöneltmektedir (Tükenmez, 2019: 4).

Yalnız gezginler, paket tur satın alan ve kitle turizmine katılan turistlerden farklı ihtiyaç, beklenti ve tutumlara sahip büyüyen bir pazar bölümü olarak kabul edilmektedir. Bu yeni küresel seyahat dünyasında "yeni ziyaretçiler” bireysellik, esneklik, öngörülemezlik ve çevre bilinci ile karakterize edilmiştir (Frohlick, 2013). Yalnız seyahat eden turistler ikamet ettiği yerden yalnız ayrılır, kendi başlarına seyahat ederler. Tatil öncesi seyahat planlamasında (destinasyon seçimi, ulaşım araçları, konaklama ve yiyecek içecek imkanları) ve tatil sürecindeki katılacakları rekreaktif etkinliklerden ve diğer yararlanacağı hizmetlerden kendileri sorumludur. Yalnız seyahat eden turist bireysel olarak seyahat etse de, tatilleri boyunca yalnız kalacakları anlamına gelmez. Bu turistler grubu diğer ziyaretçilerle karşılaştırıldığında, tatil beldesinde daha uzun süre kalmaktadır (Bond, 2015).

Yapılan doküman analizi sonucunda yalnız seyahat edenlerin seyahat deneyimleri ve motivasyonları üzerine çalışmalar (örn. Riley, 1988; Murphy, 2001; Noy, 2004; Harman, 2014; Arslantürk ve Unur, 2019) olduğu tespit edilmiştir. Bu çalışmalarda yalnız seyahat eden, bağımsız kadın gezginlerin motivasyonları ve deneyimlerinin incelendiği görülmektedir. Alan yazınında Z kuşağında yer alan yalnız seyahat eden turistlerin seyahat motivasyonu ve deneyimleri ile ilgili çalışmaya rastlanmamıştır. Çalışmanın amacı Z 
kuşağında bulunan yalnız seyahat eden turistlerin seyahat motivasyonları ve deneyimlerini incelemektir. Böylelikle $\mathrm{Z}$ kuşağı yalnız seyahat eden turistlerin seyahat motivasyonları ve deneyimlerine ilişkin veriler elde edilerek alan yazına katkı sağlaması hedeflenmiştir. Çalışmada; yalnız seyahat hareketi, seyahat motivasyonu ve deneyimi ile Z kuşağı seyahat motivasyonu ve deneyimi konularına değinilmiş ve araştırma yönteminin açıklanması, bulguların sunulması, sonuç ve öneriler ile sonlandırılmıştır.

\section{Kavramsal Çerçeve}

\subsection{Yalnı Seyahat Hareketi}

Toplumsal, politik, kültürel ve teknolojik gelişmeler, özellikle turistik tüketicilerin seyahatlerine ve seyahatlerinden doğan ihtiyaçları giderme amaçlı yapmış oldukları konaklama, ulaşım, yeme içme gibi tercihlerinde değişimlere neden olmaktadır (Tükenmez, 2019: 30). Bu değişimler ile beraber yalnız seyahatlere yönelik bir talep ortaya çıkmaktadır. Yalnız seyahatlerin geçmişi sırt çantalı turistlerin gerçekleştirdiği seyahatlere uzanmaktadır. 1990'lı yıllarda "sırt çantalı turist" terminolojisi, bir kâşif veya araştırmacı kavramları için yaygın bir biçimde kullanılmaya başlanmıştır. Sırt çantalı turistler turizm literatüründe sıkça kullanılmasına rağmen günümüzde, yalnız seyahat hareketi daha yaygın hale gelmekte, yalnız seyahat etmek ve keşif hissini yaşamak isteyen bireyleri tanımlamaktadır (Pereira ve Silva, 2018: 135). Kısaca yalnız seyahat, kişinin tek başına evinden ayrılarak seyahat etmesini ifade etmektedir. Sosyal yapılardaki yaşam tarzlarındaki değişimler nedeniyle yalnız seyahat edenler turizm pazarının en hızlı büyüyen segmentlerinden biridir (Mill ve Morrison, 2009; Chung, Baik ve Lee, 2017: 484). Bu turist tipi genç ve bütçe turistleri olarak uzun süre tatil yapan bireylerdir (Loker-Murphy ve Pearce, 1995). Çoğu sırt çantalı turist tek başına veya küçük gruplar halinde seyahat etmekte, uygun seyahat koşulları aramakta olup konaklama ve turizm tercihlerinde oldukça esnek davranmaktadır (Scheyvens, 2002). Bu turist grubu bir keşif yolculuğu olan deneyimler aramakta ve alışılmadık yerleri keşfetmek istemektedir (Haigh, 1995).

Turizm alan yazınında yalnız seyahat eden ve bağımsız gezgin olarak adlandırılan çeşitli terimler kullanılmaktadır. "Yalnız" ve "bağımsız" gezginler arasında ayrım yapmak önemlidir. Bağımsız gezginler "bir pakette turla ya da bir grupta seyahat etmeyen" bireyleri tanımlamaktadır (Wilson, 2004: 8). Bu turistler kitle turistlerinden farklı olarak özel nitelik ve seyahat motivasyonlarına sahip olan ve büyüyen bir pazar segmentini temsil etmektedir. Bağımsız gezginler grup halinde veya kapsamlı turlarda seyahat etmemektedirler (Gomes ve Montenegro, 2016). Ziyaret etmeyi istedikleri destinasyonları planlama konusunda esnek 
olmalarının yanı sıra turizm programlarını düzenleme özgürlüğüne de sahiptirler. Bu nedenle, turist deneyimlerini kişiselleştirmeyi ve seyahat, ulaşım, konaklama ve aktiviteler gibi tüm turistik faaliyetler için rezervasyon yapmaktadırlar (Hyde ve Lawson, 2003). Diğer yandan, turizm literatüründe yalnız gezginler; tek başına destinasyona gelen kişiyi ifade etmektedir (Yang ve Tung, 2017). Başka bir deyişle, "yalnız" kavramı, seyahat etme durumunu değil, bireysel varış durumunu ifade etmektedir (Laesser, Beritelli ve Bieger, 2009). Bu durum, turistlerin tüm seyahatleri sırasında yalnız kalacaklarını anlamına gelmez çünkü yerel toplumla, turizm sektöründe hizmet veren kişilerle ve diğer turistlerle temasa geçmelerini engellemek mümkün değildir (Wilson, 2004; Yang ve Tung, 2017). Birçok turistle iletişim ve ilişki kurabilirler, bu nedenle başkalarıyla seyahatlerine devam etme olasılıkları da bulunmaktadır. Yalnız seyahat edenler, bağımsız gezginler gibi özgürlük ve esneklik gibi niteliklere sahiptirler; sonuç olarak kendi tur programlarından ve faaliyetlerinden sorumludurlar (Hyde ve Lawson, 2003; El Gamil, 2018). Bu anlamda, "yalnız seyahat" kavramı, tatilde sürecinde değil, sadece kişinin destinasyona varış durumunu ifade etmektedir. Yalnız gezginler ikamet ettikleri yerden yalnız ayrılırlar, öncelikle tek başına seyahat ederler (yol boyunca başkalarıyla buluşabilir veya bazen de turları kullanabilirler) ve yalnız seyahat planlarından, seçimlerinden ve aktivitelerinden kendileri sorumludurlar (Wilson, 2004: 9). Çeşitli çalışmalarda yalnız seyahat farklı türlerde değerlendirilmiştir. Bunlar; varış durumuna göre (McNamara ve Prideaux, 2010), medeni durumuna göre (Chung vd., 2017), yolculuk boyunca yalnız seyahat etme duruma göre (Bianchi, 2016) ve de çoğunlukla tek başına seyahat etme durumuna göre (Wilson, 2004) sınıflandırılmıştır (Yang, 2020: 2).

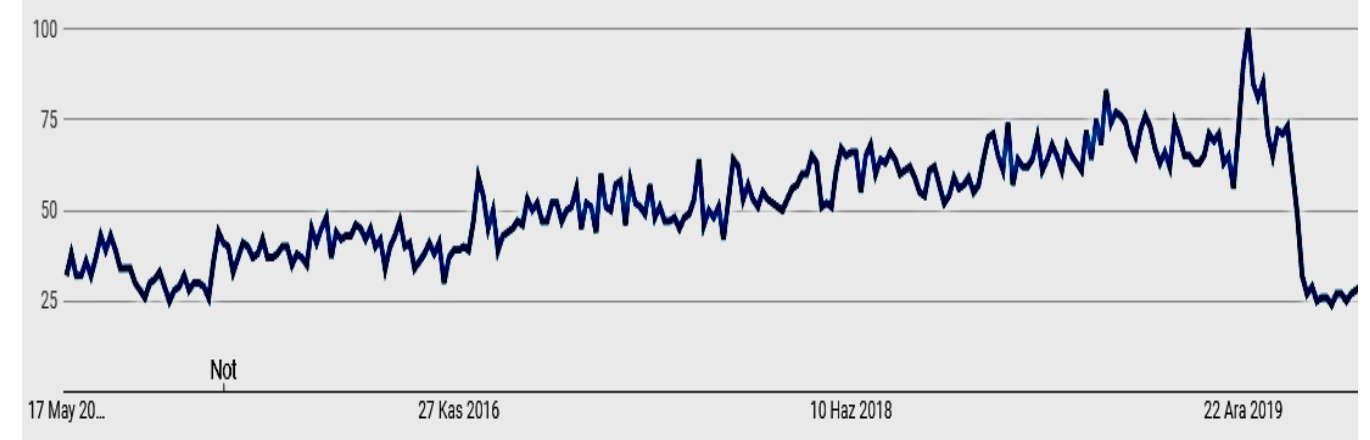

Şekil 1. Son 5 Yıılda Dünya Çapında Yalnız Seyahat Hareketine Gösterilen İlgi (20152019)

Kaynak: Google Trends, 2020. 
Mehmetoğlu, Dann ve Larsen'in (2001) Norveç'teki yalnız gezginler hakkında yapmış oldukları çalışma, yalnız seyahat eden turistlerin motivasyonlarını açıkça inceleyen ilk araştırmalardan biridir. Yalnız seyahat eden turistler (yani, uygun bir seyahat arkadaşı bulamayanlar) ve kendi seçimleriyle yalnız seyahat edenler arasındaki farkı incelemişlerdir. Kendi seçimleriyle yalnız seyahat edenler için, rahatlık, özgürlük, esneklik ve yalnızlık dahil olmak üzere derinlemesine görüşmeler yoluyla bir dizi sosyal ve psikolojik motivasyon belirlemişlerdir. Sonuçlar aynı zamanda kendi seçimleriyle yalnız seyahat eden turistlerin bir tecrit (her şeyden soyutlanmak) duygusu için yalnız seyahat etmediklerini, ancak yalnız hareket etmenin yerel halk ve/veya diğer gezginlerle daha fazla etkileşime imkânı verdiğini göstermiştir. Riley (1988), sırt çantalı gezginlerin motivasyonlarını ve deneyimlerini incelemiştir. Açıkça yalnız seyahat davranışları üzerine bir çalışma olmasa da yazar, görüştüğü gezginlerin çoğunun yalnız seyahat etmeyi tercih ettiğini, "seyahat özgürlüğünü tercih etmelerini ile seyahat etmenin kısıtlamalarını farklı zamanlar, bütçe sınırlamaları ve kaynak yönetimi konuları” arasında ilişki olduğu sonucunu elde etmiştir.

\subsection{Seyahat Motivasyonu ve Deneyimi}

Motivasyon, bir kişiyi memnun etmesi muhtemel görülen, belirli eylem türlerine yönlendiren bir ihtiyaç veya durumdur (Moutinho, 2000). Motivasyon aynı zamanda biyolojik bir ihtiyacı veya psikolojik arzuyu yerine getirmek için bireyi harekete geçiren güç (Fridgen, 1996) olarak tanımlanmaktadır. Seyahat motivasyonu insanların neden seyahat ettiği ile ilgilidir (Hsu ve Huang, 2008). Seyahat motivasyonları çok çeşitli insan davranışlarını ve insan deneyimlerini kapsamaktadır. $\mathrm{Bu}$ motivasyonlar; rahatlama, heyecan arayışı, arkadaşlarla sosyal etkileşimler, macera, aile etkileşimleri, statü, fiziksel zorluklar ve rutin veya stresten kaçma gibi faktörleri kapsamaktadır (Pereira ve Silva, 2018: 135).

Seyahat motivasyonu, turist davranışını açıklamada anahtar bir faktör olarak görülmektedir (Mansfield, 1992; Fodness 1994; Crompton ve McKay 1997; Gnoth 1997). Motivasyon, bireyi eyleme geçiren önemli bir faktör olduğu için, seyahat kararının nasıl alındığını anlamak faydalı olmaktadır. Seyahat motivasyonu; potansiyel bir turistin belirli bir destinasyona yönelik olarak hareket etmesine neden olan ihtiyaçlar ve tutumlar kümesidir (Pizam, Neumann ve Reichel, 1979). Lubbe'e göre (1998) seyahat motivasyonu, insanların belirli ihtiyaçlarının farkına varmaları ve belirli destinasyonların bu ihtiyaçlara cevap verebileceğini algılamalarıdır.

Deneyim; bireyin içinde yaşadığı duygusal, bedensel, entelektüel ve ruhsal değişimleri ifade etmektedir (Pine ve Gilmore, 1998). Deneyim genel olarak iki boyutta incelenmektedir. 
Birinci boyut müşteri katılımıdır. Kişilerin performansa herhangi bir etkilerinin bulunmadığı pasif katılımı oluşturmaktadır. Pasif katılımda, bireyler, olayları ve etkinlikleri pasif bir şekilde yani sadece izleyici olarak gözlemlemektedir (Song, Lee, Park, Hwang ve Reisinger, 2015). İkinci boyut ise kişilerin olayı veya performansı bizzat etkilediği aktif katılımdan oluşmaktadır. Deneyim olarak tanımlanan faaliyetlerin meydana gelebilmesi için kişilerin aktif olarak katılımı gerekmektedir. Deneyim boyutlarının bir yönü zihinsel olarak, dikkatini vermeye ve öğrenmeye odaklanır, diğer yönü ise fiziksel anlamda dâhil olmaya odaklanır (Lin, 2006). Aktif, pasif katılım, özümseme ve sarmalanma boyutları dört temel deneyim alanını oluşturmaktadır. Bu dört temel deneyim alanı; estetik, eğlence, eğitimsel ve kaçış deneyimleridir (Kim, Ritchie ve McCormick, 2012).

Seyahat ve turizm tercihleri için başlıca temel güdüler aşağıda verilmektedir. Bu güdüler Smith (1977), Murphy (1985) ve McIntosh ve Goeldner (1990) çalışmalarına dayanmaktadır. Uluslararası seyahat ve turizm anketlerinde kullanılmak üzere Dünya Turizm Örgütü tarafından geliştirilen genel seyahat amacı sınıflandırması ile geniş ölçüde uyumludur. Seyahat ve turizmin temel güdüleri (Middleton ve Clarke, 2001):

- İş ile ilgili nedenler: Özel sektör ve kamu sektörü işletmeleri, konferanslar, toplantılar, sergiler ve kısa süreli kursları kapsamaktadır. Örneğin, havayolu da dâhil olmak üzere iş amaçlı seyahatler için ikamet ettikleri yerden uzaklaşan havayolları personeli, kamyon şoförleri, servis mühendisleri vb. bu grupta yer almaktadır.

- Fiziksel/fizyolojik nedenler: Kapalı alan spor faaliyetleri ve aktif açık hava rekreasyonuna katılımı kapsamaktadır. Örneğin; golf, yürüyüş, yelken, kayak vb., ile sağl1k, zindelik ve iyileşme için gerçekleştirilen faaliyetler.

- Dinlenme/rahatlama/günlük yaşamın stresinden kurtulma nedenleri; Bir plajda sıcaklık/güneş/dinlenme ihtiyacını giderme vb. faaliyetler bu grupta yer almaktadır.

- Kültürel/psikolojik/kişisel eğitim amaçlı nedenler: Festival, tiyatro, müzik gösterilerine katılım, müze ziyaretleri, kurslar ve faaliyetler dâhil kişisel ilgi alanlarına katılım entelektüel, zanaat ve diğer boş zaman arayışlarını içerir. Kültürel ve /veya doğal miras alanlarını ziyaret etmek (eko turizm dâhil) de bu grup da yer almaktadır.

- Sosyal/kişilerarası ve etnik nedenler: Arkadaş ve akraba ziyaretlerini, sosyal görevler için seyahatleri - düğünlerden cenaze törenlerine- kapsamaktadır. Bireysel nedenlerle seyahat edenler (örneğin iş veya sosyal görevler), doğum yerini ziyaret edenler ve tarihsel köklerini keşfetmek isteyenler vb. bu grupta yer almaktadır. 
- Eğlence/zevk amaçlı nedenler: Spor karşılaşmaları/ diğer seyirci etkinliklerini izlemek, tema parklarını/eğlence parklarını ziyaret etmek, rutin olmayan boş zaman alışverişi yapmak vb. gibi faaliyetleri kapsamaktadir.

- Dini nedenler: Hac organizasyonlarına katılmak, meditasyon ve inzivaya çekilme vb. nedenler olarak sınıflandırılabilir.

Turist motivasyonu ile ilgili araştırmaların çoğu itici ve çekici faktörler kavramı üzerinde yoğunlaşmaktadır (Crompton, 1979). Crompton (1979), itici faktörleri tatil yapma arzusu, bir tatil için bireydeki sosyo-psikolojik dürtüler olarak tanımlarken, Dann (1977), itici faktörleri turisti tatile hazırlayan kaçış, nostalji arayışı gibi nedenler olarak tanımlamaktadır. Çekici faktörler ise bir turisti belirli bir destinasyona çeken kültür, tarih, güneş ve deniz gibi destinasyona ait özelliklerden oluşmaktadır (Dann, 1977). Çekici faktörler, güdüleri uyarmayı sağlayan (Crompton, 1979) destinasyonun algılanan özellikleri (Prayag ve Ryan, 2011) şeklinde de tanımlanabilmektedir.

Pearce (1982), Maslow'un ihtiyaçlar hiyerarşisini turistlerin motivasyonuna ve davranışlarına uygulayarak turistlerin kendini gerçekleştirme, sevgi, aidiyet ve fizyolojik ihtiyaçların karşılanması nedeniyle destinasyonlara çekildiğini savunmaktadır (Esichaikul, 2012: 49). Literatürde yalnız seyahatlere ilişkin motivasyonlar; özgürlük, zorluklar ve başa çıkabilme, kendini tanıma, diğer gezginlerle iletişim, yeni yaşam tarzları, rutinden kaçış, öğrenme, yeni deneyimler, macera ve boş zaman olarak ele alınmaktadır (Pereira ve Silva, 2018: 135).

Yalnız seyahat eden turistlerin motivasyon ve deneyimlerine yönelik olarak yapılan çalışmalar incelendiğinde, genel olarak yalnız seyahat eden kadın turistlerin örneklem ele alındığı görülmektedir. Z kuşağında yer alan turistlerin incelendiği bir çalışmaya rastlanmamakla birlikte yapılan çalışmalardan bazıları şunlardır: Chiang ve Jogaratnam (2006) tarafından yapılan araştırmada yalnız seyahat eden kadınlar için beş motivasyon boyutu; deneyim, kaçış, rahatlama, sosyal ve benlik saygısı olarak tespit edilmiştir. Çalışmada beş motivasyon faktörü, katılımcıların demografik ve seyahat özelliklerine göre önemli ölçüde farklılık göstermiştir. Esichaikul (2012) çalışmasında, Tayland'a gelen yaşlı Avrupalı turistlerin seyahat motivasyonları, davranışları ve gereksinimlerini incelemiştir. Araştırma bulguları, Avrupalı yaşlı turistlerin başlıca seyahat motivasyonlarının dinlenme ve rahatlama olduğunu göstermiştir. Avrupalı yaşlı turistlerin üç temel gereksinimi; destinasyonun güvenliği, konaklama yeri ve doğal cazibe merkezlerinin varlığıdır. Pereira ve Silva (2018) çalışmalarında, kadın turistlerin motivasyon ile yalnız seyahat deneyimleri arasındaki ilişkiyi incelemişlerdir. 


\subsection{Z Kuşağı Seyahat Motivasyonu ve Deneyimi}

Yalnız seyahat hareketi yaş gruplarına göre farklı motivasyon kaynaklarına bağlı olarak gerçekleşmektedir. Genel olarak literatürde yaş gruplarının dağılımı, X (1965-1980 doğumlu), Y (1981-1994 doğumlu) ve Z (1995'ten sonra doğan) kuşaklarından oluşmaktadır (McCrindle, 2014: 57). Bu yaş grupları arasında Z kuşağında yer alan turistler; çoğunlukla ailelerinden uzakta yaşamakta ve sık sık seyahat etmek için daha fazla boş zamanları bulunmaktadır (Hsu ve Sung, 1997). Z kuşağının seyahat motivasyonlarını incelemek onların talep ve beklentilerini karşılayabilmek oldukça önemlidir. Phocus Wire'a göre (2020) "Booking.com tarafından yalnız seyahat eden turistler üzerine yapılan araştırmaya göre, Z kuşağı turistleri aileleri birlikte seyahat ettiklerini ve aileleri ile seyahat etmelerinin nedenini \% 42'si kendi ekonomik güçleri olmadığından kaynaklandığını belirtmektedirler. Bununla birlikte araştırmaya katılanların \% 34'ünün önümüzdeki on yılda en az bir kez kendi başına seyahat etmeyi planladığını ifade etmişlerdir. Ayrıca, araştırmaya katılanların üçte biri seyahat ederken aslında yalnız olmayı tercih ettiklerini ifade etmekte ve yaklaşık \% 20'si yalnız bir sırt çantasıyla seyahat etmek veya boş zaman geçirmek istediklerini"” belirtmişlerdir.

Z kuşağı turistleri genellikle bilgisayar ve bilişim teknolojileri konusunda uzman olan kişilerdir. Ana bilgi kaynakları internettir. Z kuşağı çok farklı seyahat motivasyonlarına sahip olmakla birlikte çevre korumaya duyarlı ve açık fikirli bir yapıya sahiptirler. Ayrıca bu grup seyahatlerinden oldukça yüksek beklentiye sahiptirler. Konaklama biçimleri genellikle hedonistik bir davranışa (haz ve mutluluk veren bir davranış) dönüşmekte olup, turizm onlar için bir eğlence, sosyalleşme ve kendini yenileme anı olarak nitelendirilmektedir (Haddouche ve Salomone, 2018: 70).

Z kuşağı çoğunlukla internet, akıllı telefonlar, bilgisayarlar, dijital medya, wi-fi erişim imkânlarını yoğun bir şekilde kullanmaktadır (Tulgan, 2013). Z kuşağı satın alma davranışları arasında düşük maliyetli destinasyonları tercih etme, son dakika kararları, indirim firsatlarını yakalama, ağızdan ağıza iletişim kaynakları yer almaktadır (Mignon, 2003).

Tükenmez (2019), Türkiye'deki yalnız seyahat eden kadınların seyahat kısıtlamaları, seyahat motivasyonları, tercihleri ve seyahat deneyimlerini incelemiştir. Buna göre, Türkiye'de yalnız seyahat eden kadınları kısıtlayan en önemli unsur, kişisel kısıtlardan biri olan korku faktörüdür. Araştırmada kadınları en çok motive eden unsur, itici bir motivasyon olan yaşadıkları rutin hayattan uzaklaşma isteğidir. Yalnız seyahate dair en önemli yaşadıkları deneyim ise, kendilerini seyahatleri boyunca özgür hissetme duygularıdır. Osman vd. (2020), Vietnamlı yalnız seyahat eden kadın turistlerin seyahat motivasyonları ve deneyimlerini 
incelemek üzere yaptıkları araştırmada seyahat kısıtlarının kadın ve yalnız olmak ve Asya kökenli olmakla ilgili olduğu sonucuna ulaşmışlardır. Haddouche ve Salomone, (2018) tarafından yapılan çalışmada Z kuşağı ve turist deneyimi; turist hikâyeleri ve sosyal ağların kullanımı ile ilişkilendirilmiştir. Robinson ve Schänzel (2019) tarafından yapılan çalışmada Z kuşağının seyahat deneyimini incelenmektedir.

\section{Araştırma Yöntemi}

Çalışmada, Z kuşağında yer alan yalnız seyahat eden turistlerin, seyahatlerine yönelik motivasyon kaynakları ve bu süreçteki deneyimleri incelenmiştir. Çalışmada, nitel araştırma yöntemlerinden yararlanılmıştır. Nitel araştırma, disiplinler arası bütüncül bir bakış açısını temel alarak, araştırma problemini yorumlayıcı bir şekilde incelemeye imkân sağlayan bir yöntemdir. Üzerinde araştırma yapılan konuları kendi bağlamında ele alınarak, insanların onlara yükledikleri anlamlar incelenmektedir (Altunışık vd., 2010: 302; Karataş, 2015: 63). Çalışmada, elde edilen verilerin incelenmesinde betimsel analiz yöntemi ile birlikte, bu verileri açıklayan kavram ve temalara ulaşılması amacıyla içerik analizi yönteminden de yararlanılmıştır (Yıldırım ve Şimşek, 2005: 56; Kuzu, 2013: 35). Betimsel analiz yöntemi ile elde edilen bulgular direkt olarak aktarılırken, içerik analizi yönteminde veriler çeşitli kategorilere ayrılmıştır. İçerik analizi yapılırken, birbirine benzeyen verileri belirli kavramlar ve temalar ekseninde birleştirmek ve bunları okuyucunun anlayabileceği bir biçimde düzenleyerek yorumlanmıştır (Yıldırım ve Şimşek, 2016: 242). Araştırmanın güvenirliğini belirlemek amacıyla görüşme verileri bir alan uzmanı turizm akademisyene incelemesi ve kodlaması için gönderilmiştir. Alan uzmanı ve yazarlar ve tarafindan yapılan kodlama formları, güvenirlilik testlerinden biri olan Kappa testine tabi tutulmuştur. Kappa analizi sonucunda, Kappa Güvenirlik Katsayısı değeri 0.79 çıkmıştır. Kappa testi sonucu 0.40 değeri ile 0.75 değeri arasında olduğu için yeterli kabul edilmektedir (Şencan, 2005).

Araştırmada, yarı yapılandırılmış bir görüşme formu kullanılmıştır (Yıldırım ve Şimşek, 2008: 120). Araştırma soruları oluşturulurken alan yazından ve uzman görüşlerinden yararlanılmıştır. Araştırmada toplanan ayrıntılı verilerden yola çıkarak probleme ilişkin ana temalar ortaya çıkartılmış ve kodlamalar yapılmıştır. Görüşme soruları kişisel bilgiler, tatil süreci, seyahat deneyimleri ve motivasyon kaynaklarını öğrenmek amacıyla hazırlanmıştır. Görüşmede kullanılan açık uçlu sorular aşağıda verilmiştir;

\section{Görüşme Soruları:}

1. Yaşını/Cinsiyetiniz

2. Daha önce bu şekilde bir yalnız seyahat yaptınız mı? 
3. Konaklama yerini nasıl ayarladınız, nerede kaldınız?

4. Gideceğiniz destinasyona ulaşımı nasıl gerçekleştirdiniz?

5. Gittiğiniz destinasyonda yiyecek içecek işletmelerini nasıl buluyorsunuz?

6. Sizi yalnız seyahate çıkmaya teşvik eden motivasyon kaynağınız nelerdir?

7. Gerçekleştirdiğiniz yalnız seyahatlerde ne kadar para harcama yapıyorsunuz?

8. Katıldığınız yalnız seyahat türü nelerdir?

9. Yalnız seyahatiniz sırasında yaşadığınız olumlu ve olumsuz deneyimler nelerdir.

\subsection{Araştırmanın Çalışma Grubu}

Görüşmeye katılan katılımcıların özelliklerine ilişkin genel bilgiler aşağıda grafikler halinde verilmiştir. Katılımcıların tamamı yalnız seyahat faaliyetine katılmış ve süreci deneyimlemişlerdir.

\begin{tabular}{|c|c|c|c|c|c|}
\hline $\begin{array}{c}\text { Katılımcı } \\
\text { Kodu }\end{array}$ & Cinsiyet & Yaş & $\begin{array}{c}\text { Medeni } \\
\text { Durumu }\end{array}$ & Eğitim Durumu & $\begin{array}{c}\text { Yalnız } \\
\text { Seyahat Sayısı }\end{array}$ \\
\hline K1 & Erkek & 22 & Bekâr & Üniversite Mezunu & 3 \\
\hline K2 & Kadın & 23 & Bekâr & Üniversite Mezunu & 1 \\
\hline K3 & Erkek & 23 & Bekâr & Üniversite Mezunu & 1 \\
\hline K4 & Kadın & 20 & Bekâr & Üniversite Mezunu & 2 \\
\hline K5 & Erkek & 23 & Bekâr & Üniversite Mezunu & 4 \\
\hline K6 & Kadın & 22 & Bekâr & Üniversite Mezunu & 4 \\
\hline K7 & Erkek & 21 & Bekâr & Üniversite Mezunu & 2 \\
\hline K8 & Erkek & 24 & Bekâr & Üniversite Mezunu & 6 \\
\hline K9 & Erkek & 23 & Bekâr & Üniversite Mezunu & 2 \\
\hline K10 & Erkek & 25 & Bekâr & Üniversite Mezunu & 9 \\
\hline
\end{tabular}

Araştırmanın evrenini Isparta ilinde, Z kuşağında yer alan yalnız seyahat eden turistler oluşturmaktadır. Görüşme sürecinde araştırmacıların çok sayıda katılımcıya ulaşması, sıklıkla yapılan bir hatadır (Creswell, 2002; Makatouni, 2002). Görüşmelerde sayıdan ziyade nitelik önemlidir ve tek bir katılımcıdan bile araştırma probleminin çözümü gerekli için veri sağlanabilir (Baltacı, 2019: 376). Bu bağlamda çalışmada, amaçlı örnekleme yöntemi kullanılarak yalnız seyahat eden 10 kişi ile görüşülmüştür.

Görüşmeler, Temmuz (2020) ayı içerisinde telefon yolu ile gerçekleştirilmiştir. Görüşmeler katılımcıların rızası alınarak yaklaşım 25-45 dakika kayıt altına alınmıştır. Görüşmelerde her katılımcıya bir kod (K1, K2) verilmiştir. Araştırmanın Covid-19 salgın 
sürecinde gerçekleştirilmesi nedeniyle az sayıda katılımcıya ulaşıllabilmiş̧tir. Bu da, araştırmanın kısıtını oluşturmaktadır.

\subsection{Verilerin Analizi}

Veri analiz sürecinde ses dosyalarında bulunan katılımcı ifadeleri word dökümanına aktarılmıştır. Word belgesine aktarım esnasında katılımcılara birer kod-rakam verilmiştir. Elde edilen görüşme verilerinin deşifresi nitel veri analizine olanak tanıyan bir yazılım olan MAXQDA 18 ile yapılmıştır. MAXQDA, araştırmacılar için kolaylık sağlayan ve nitel araştırmanın kendi doğasında çözümlenmesine olanak tanıyan önemli ve güncel bir yazılımdır (Besnili Memiş, 2019: 705). Bulgular kısmında detaylı ele alınacak olsa da nitel araştırma verilerinin analizinde kod-alt kod frekans grafikleri ile bir kodun alt kodlar1 ile birlikte katılımcı ifade sayılarına göre sonuçları verilmektedir.

\section{Araştırma Bulguları}

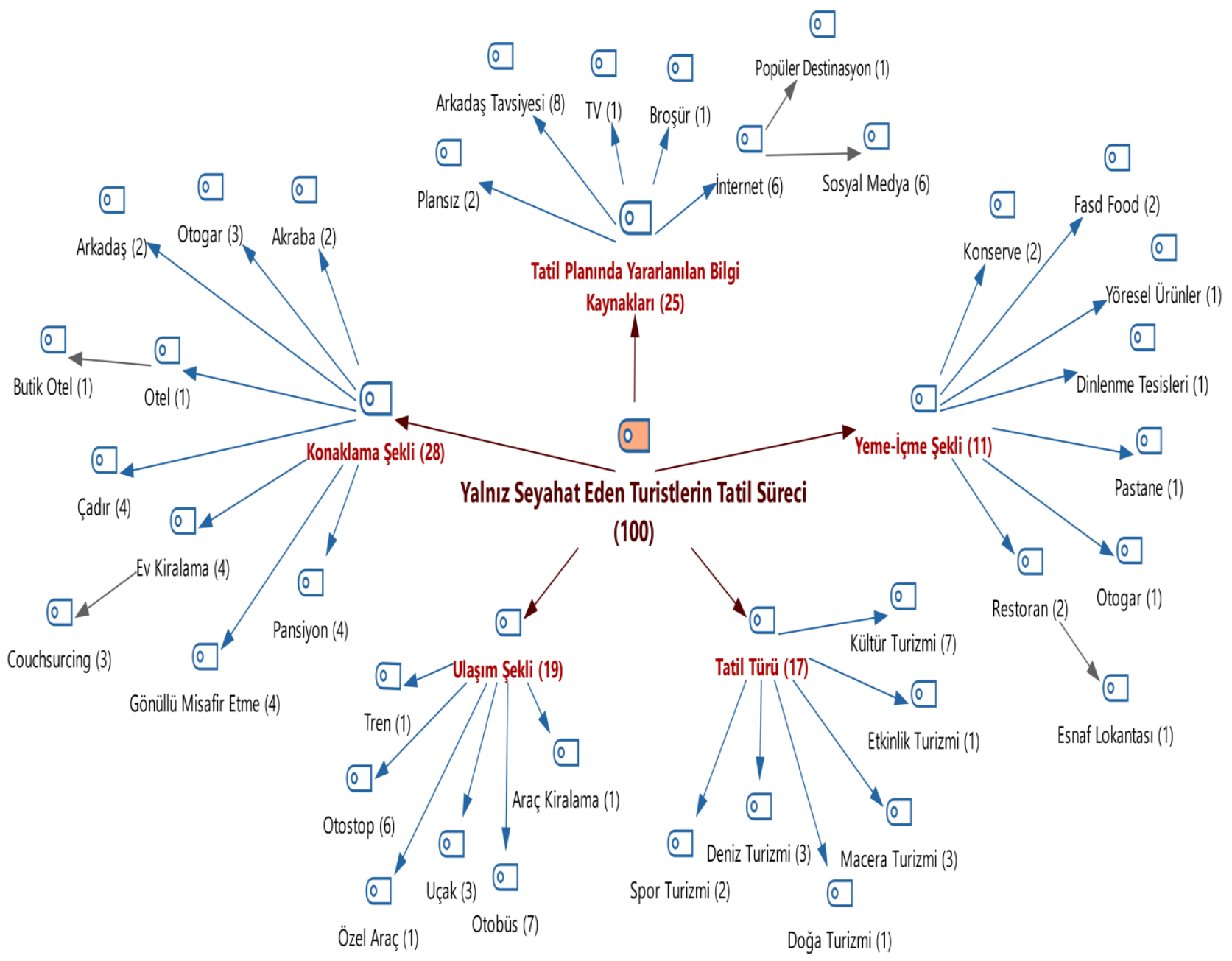

Şekil 1. Katılımcılar Tarafından Tatil Sürecine Yönelik Görüşlerinin Kodlu Bölüm Sayısına Göre Sinıflandırması 
Şekil 1'de yalnız seyahat eden katılımcıların 100 ifade ile tatil sürecinden bahsettiği görülmektedir. Bu ifadeler, "tatil planlarında yararlanılan bilgi kaynăğı”, “konaklama şekli", “ulaşım şekli”, “yeme-içme şekli” ve “tatil türü" olmak üzere 5 tema altında toplanmıştır. Tatil planlarında yararlanılan bilgi kaynağı teması altında 25, konaklama şekli teması altında 28, ulaşım şekli teması altında 19, yeme-içme şekli teması altında 11 ve tatil türü teması altında da 17 katılımcı ifadesi bulunmaktadır. Tatil planlamada bilgi kaynağı olarak, en fazla internetten 6 (sosyal medya 6 ve popüler destinasyon 1) yararlanırken en az televizyon ve broşürden yararlanılmaktadır. Katılımcılardan ikisi ise, plansız seyahati tercih etmektedir. Konaklama şekli arasında en fazla ev kiralama, pansiyon, çadır ve gönüllü misafir etme yer almaktadır. Ulaşım şekli, otobüs ve otostop yer almaktadır. Yeme-içme tercihleri arasında en fazla restoranlar, konserve ve fast food yer almaktadır. Katılımcıların en fazla kültür turizmi, deniz turizmi ve macera turizmini tercih ettiği görülmektedir.

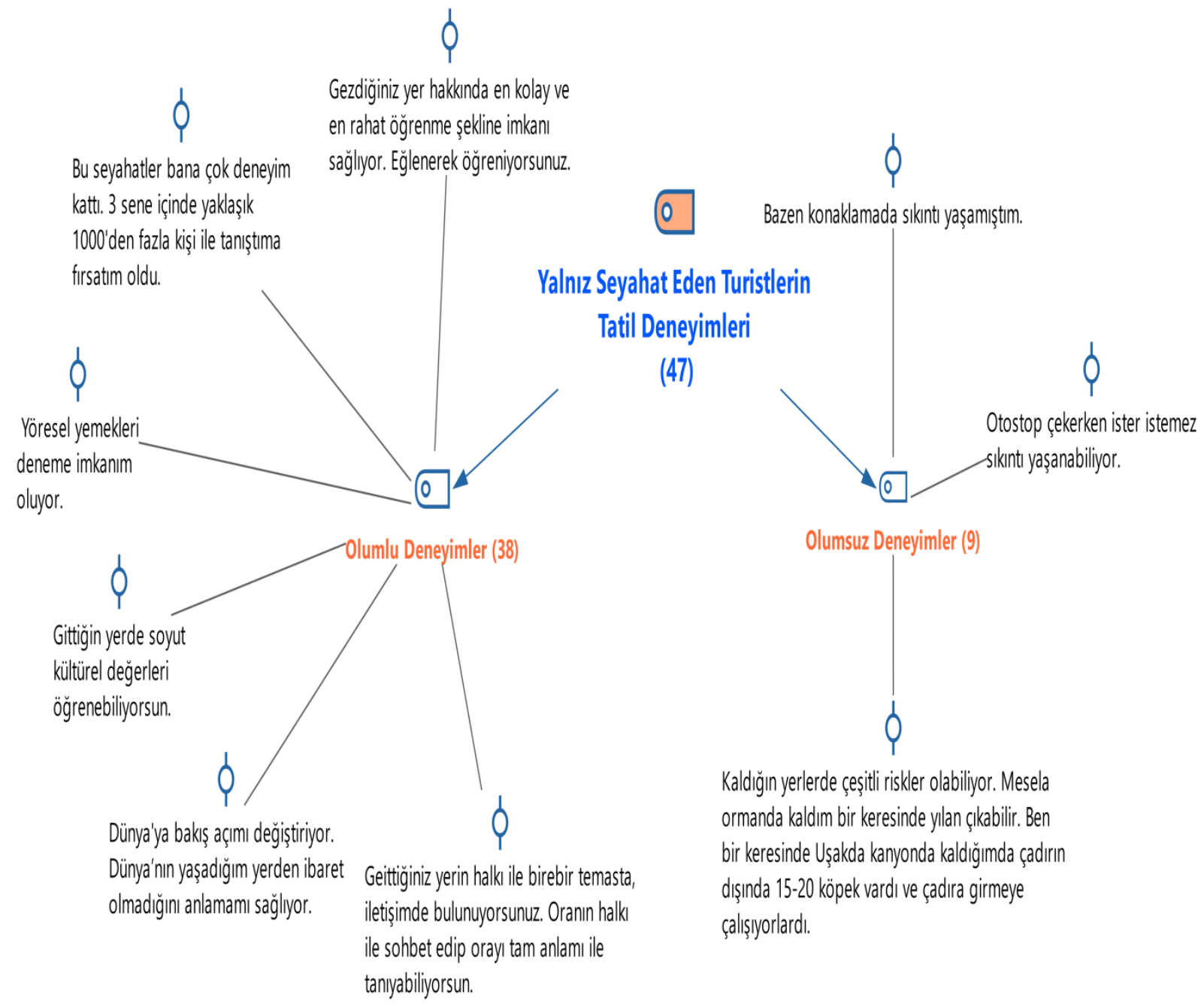

Şekil 2. Katılımcılar Tarafından Tatil Deneyimlerine Yönelik Görüşlerinin Kodlu Bölüm Sayısına Göre Sınıflandırması 
Şekil 2'de yalnız seyahat eden katılımcıların, 47 ifade ile tatil deneyimlerinden bahsettiği görülmektedir. Tatil deneyimleri olumlu ve olumsuz olmak üzere iki temaya ayrılmıştır. Araştırmada, katılımcılar 38 ifade ile olumlu deneyimlerinden bahsederken 9 ifade ile olumsuz deneyimlerinden bahsetmektedir. $\mathrm{Bu}$ veriler 1şı̆̆ında, olumlu deneyimlerin daha fazla yaşandığı görünmektedir. Aşağıda katılımcı ifadelerinden bazıları örnek olarak verilmiştir.

$>$ Katılımcıların olumlu deneyimlerine yönelik katılımcı ifadeleri;

Ben kadın olduğum için korkarak çıktım Güneydoğu Anadolu Bölgesi gezisine. Ama oraya gidince insanların çok iyi ve çok yardımsever olduğunu gördüm. Doğu insanına karşı bakış açım değişti çok sevdim çok iyi insanlar (K1, Kadın). Çok güzel bir tecrübe oldu benim için özellikle gezdiğimiz yerler hakkında bilgi sahibi oldum (K1, Erkek). Yeni insanlar tanlyorum kamplara gittiğimde özellikle ve festivallere gittiğimde, yeni arkadaşlar ediniyorum (K6, Kadın). Hayatın yaşadığım şehirden ibaret olmadığını görmek için bu şekilde yeni yerler gezmeyi yeni insanlar tanımayı çok seviyorum. Kendi ayaklarımın üzerinde durduğumu görmek çok güzel bir şey benim için (K8, Erkek). Yöresel yemekleri de denedim, Örneğin Rize Ayder yaylasında mıhlama yemiştim çok lezzetliydi. Antep'te nohut dürüm ve içli kebap ve baklavasını denedim gerçekten çok lezzetliydi. Normal bir baklavadan 4 tane yesen keser Antep baklavasindan 10 tane yesen de yersin. Antep fistıklı katmerini denedim çok güzeldi (K9, Erkek).

Katılımcıların olumsuz deneyimlerine yönelik katılımcı ifadeleri;

Çok arabaya biniyorsun bu sebeple kaza riski var. Yollar biraz tehlikeli örneğin günde 10 farkl arabaya biniyorsun. Bir hafta boyunca 100 tane arabaya biniyorsun. (K1, Erkek). Genellikle gezi planlarımı aniden yaptığım için kalacak yer bulma biraz sıkıntılı oluyor (K4, Kadın). 


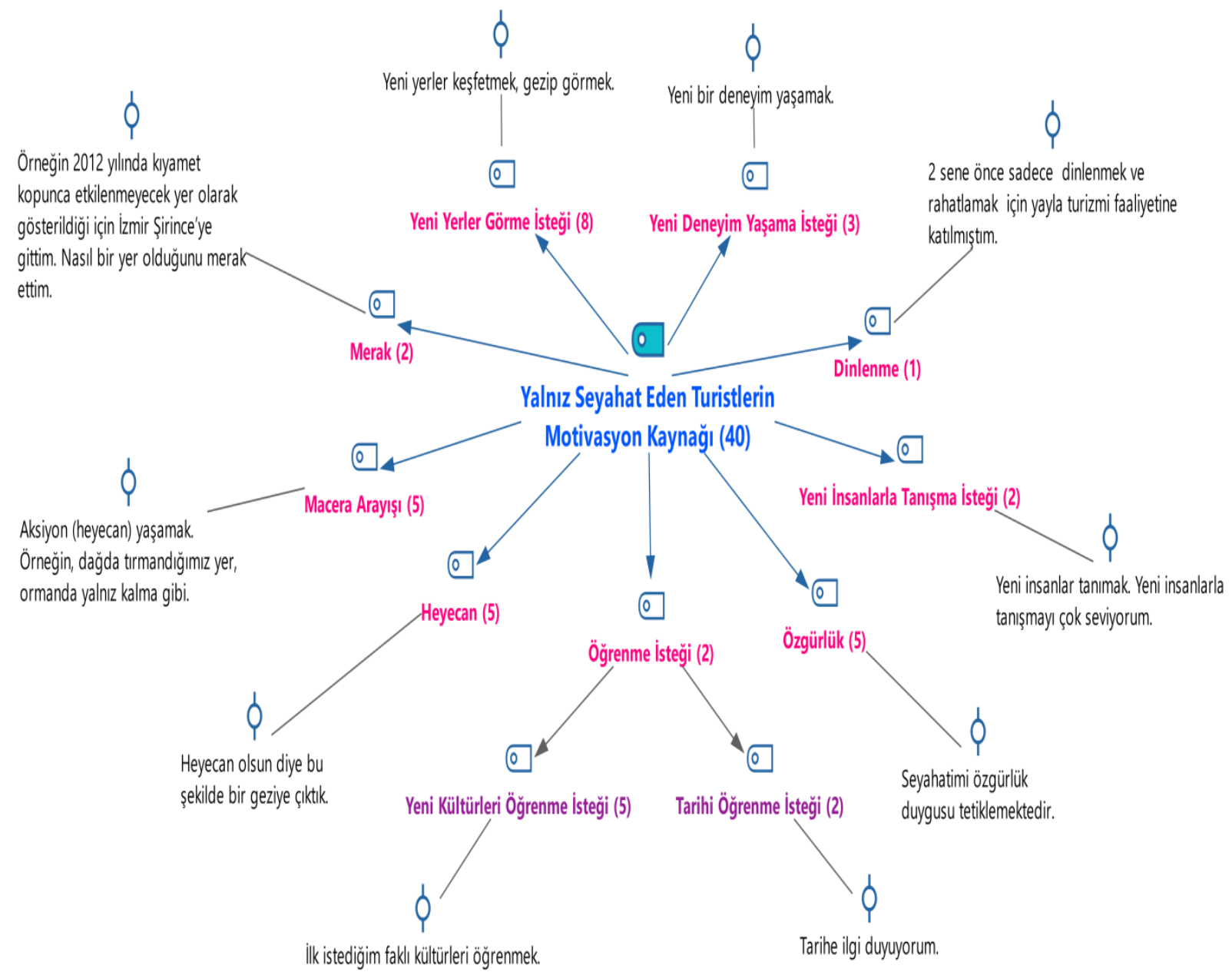

Şekil 3. Katılımcılar Tarafından Seyahat Motivasyonu Yönelik Görüşlerin Kodlu Bölüm

Sayısına Göre Sinıflandırması

Şekil 3'te görüldüğü üzere katılımcılar, 40 ifade ile seyahat motivasyon kaynağından bahsetmektedir. Yalnız seyahat motivasyonları, “merak”, “macera arayışı”, “heyecan”, “özgürlük”, “dinlenme”, “öğrenme”, “yeni yerler görme”, “yeni deneyim yaşama” ve “yeni insanlarla tanışma isteği” olmak üzere 9 temaya ayrılmıştır. Öğrenme isteği teması altında, “yeni kültürler öğrenme" ve "tarihi öğrenme" olmak üzere iki alt tema yer almaktadır. Katılımcı ifadeleri incelendiğinde en yoğun seyahat motivasyon kaynağının sırasıyla; öğrenme (9), yeni yerler görme (8), macera (5) ve heyecan (5) olduğu ortaya çıkmaktadır. En düşük motivasyon kaynağı olarak dinlenme (1) yer almaktadır. Aşağıda katılımcı ifadelerinden bazıları örnek olarak verilmiştir.

Beni seyahate yönlendiren sebeplerin başında yeni yerler görme ve oradaki insanların yaşantısına tanık olma isteği geliyor (K8, Erkek). Yeni deneyim yaşama (K9, Erkek). Araba duracak mi durmayacak mi gibi heyecan yaşama (K1, Erkek). Özgürlük duygusunu yaşama (K7, Erkek). Macera 
amactyla geziye çıkıyorum (K3, Erkek). Seyahate çıkmamda tarihe ve kültüre olan ilgim birinci strada etkili (K1, Erkek).

\section{Sonuç}

Teknolojik gelişmeler, ulaşım imkânındaki iyileştirmeler ve yaşam standartlarında gerçekleşen değişikliklere paralel olarak seyahat ve turizm alanında yaşanan gelişmeler, insanların daha fazla yalnız başına seyahat etmelerine neden olmaktadır. Turistler seyahatlerini bazen grup halinde bazen de yalnız bir şekilde gerçekleştirmektedirler. Yalnız seyahat eden turistler, farklı istekleri ve tercihlerine göre, seyahatlerine yalnız başına ya da başkaları ile devam etmektedirler. Yalnız seyahat sayesinde turistler, seyahat rotalarını bireysel olarak daha esnek ve istedikleri şekilde belirlemekte, seyahatleri sırasında kendilerini daha özgür hissederek, seyahate ilişkin beklentilerini ve isteklerini kendi istekleri doğrultusunda gerçekleştirebilmektedir. Bu durumda da motivasyonları olumlu yönde etkilenmektedir.

$\mathrm{Bu}$ araştırma, $\mathrm{Z}$ kuşağında bulunan turistlerin yalnız seyahat hareketine yönelik motivasyon ve deneyimlerinin tespit edilmesi bakımından önemlidir. Araştırma bulgularına göre, $\mathrm{Z}$ kuşağında yalnız seyahat edenlerin tatil planlamasında sosyal medyanın önemli bir yeri olduğu görülmektedir. Ulaşım şekli olarak genellikle otobüs ve otostop kullanılmaktır. Konaklama şekli olarak çoğunlukla ev kiralamanın görülmesi ile birlikte çadır da tercih edilmektedir. Yeme-içme ihtiyacının karşılanmasında gezginler, sıklıkla uygun fiyatll, pratik ve yöresel olmasını tercih etmektedir. Katılımcılar, seyahat süreci boyunca genellikle olumlu deneyimler elde ettiğini belirtmişlerdir. Katılımcılar, yeni yerler görme, yeni insanlar ile tanışma, özgür olma, hem gezip hem de öğrenme, yöresel lezzetleri tatma gibi olumlu deneyimleri yaşadıklarını ifade etmişlerdir. Yalnız seyahat etme sürecinde, bazen gezilerin plansız yapılmasından dolayı konaklama sorunu yaşanmaktadır. Bununla birlikte çok fazla ulaşım aracı değiştirilmesinden dolayı da tehlike arz etmesi ve özellikle çadırda kaldıkları durumlarda çadır kurdukları ortamın güvenli olup olması gibi olumsuzluklar da yaşanmaktadır. Yalnız seyahat sırasında karşılaştıkları tüm olumsuzluklara rağmen katılımcılar, yalnız seyahate devam edeceklerini ifade etmişlerdir. Ayrıca tüm tatil sürecinde kendi kararlarını kendileri verdiği için özgüvenlerinin arttığını da ifade etmişlerdir.

Alan yazınında yalnız seyahat eden turistler üzerine yapılan çalışmalar genellikle kadınlar üzerine yoğunlaşmaktadır. Tükenmez (2019) yaptığı çalışmada; Türkiye'de yalnız seyahat eden kadınların bu seyahatler için onları en çok motive eden unsurun rutin hayattan uzaklaşma isteği olduğunu tespit etmiştir. Yalnız seyahat eden turistlerin seyahat motivasyonu 
ve deneyimi Z kuşağı örneği çalışmasında seyahat motivasyonları olarak öğrenme isteği, yeni yerler görme isteği, macera arayış1, heyecan, merak ve özgürlük olarak tespit edilmiştir. Z kuşağı seyahat motivasyonları ile Tükenmez (2019) ile farklılıklar taşımaktadır. Z kuşağının farklı motivasyonlar ile seyahat ettikleri ifade edilebilir.

Aslantürk ve Unur (2019) çalışmalarında yalnız seyahat eden kadınların; bağımsız/özgür olma, kendilerini keşfetme, yenilenme amacıyla seyahat ettiklerini tespit etmişlerdir. Ayrıca yalnız seyahat eden kadınların destinasyon seçiminde dikkat ettikleri en önemli faktörün güvenlik olduğunu tespit etmişlerdir. Benzer şekilde Kaba ve Emekli (2018) çalışmalarında da yalnız seyahat eden kadın gezginlerin destinasyon seçiminde dikkat ettikleri öncelikli faktörün güvenlik olduğunu tespit etmişlerdir. Aslantürk ve Unur (2019) çalışmalarında yalnız seyahat etmenin risklerine rağmen kişisel gelişim, yeni dostluklar edinme ve yerel halkın olumlu desteğini alma gibi olumlu faktörlerin etkisi ile kadınların cesaret kazandığı ve yalnız seyahat etmeye devam edecekleri sonucuna ulaşmışlardır. Yalnız seyahat eden turistlerin seyahat motivasyonu ve deneyimi $\mathrm{Z}$ kuşağı örneğinde katılımcıların seyahatleri ile ilgili olumlu deneyimleri arasında; eğlenerek öğrenme, gezdiği yerler ile ilgili bilgi sahibi olma, dünyaya bakış açılarının değişmesi, gittikleri yerlerdeki yerel halk ile birebir temasta bulunma, yöresel yemekleri deneme fırsatı bulma ve kendi ayakları üzerinde durma olarak ifade etmişlerdir. Yalnız seyahatlere katılan Z kuşağı turistleri seyahatlerinden memnun kaldıklarını belirtmişılerdir. Bu doğrultuda iki çalışma benzer sonuçlar tespit edilmiştir.

Osman vd. (2020) yaptıkları çalışmada Vietnam'da yaşayan yalnız seyahat eden kadın turistlerin seyahat kısıtlarının yalnız olmak ve Asya kökenli olmak olduğunu belirtmişlerdir. Yalnız seyahat eden turistlerin seyahat motivasyonu ve deneyimi $Z$ kuşağı örneğinde araştırmaya katılan katılımcılar yalnız seyahatleri sırasında yaşadıkları olumsuzluklar arasında ekonomik satın alma güçlerinin yetersiz olduğunu ve yalnız seyahatlerinde ulaşım, konaklama, yeme-içme vb. ihtiyaçlarını karşılamak için en uygun seçenekleri değerlendirdiklerini belirtmişlerdir. $\mathrm{Bu}$ bağlamda iki çalışmanın sonuçları farklılık göstermektedir.

Çalışmada Z kuşağında yer alan ve ekonomik açıdan gelir elde eden katılımcıların yalnız seyahatleri sırasında daha fazla harcama yaptıklarını görüşmeler sırasında belirtmişlerdir. $\mathrm{Bu}$ açıdan gelir durumlarına göre de gidilen yerler, ulaşım ve konaklama tercihleri ve tatilleri süresince yaptıkları harcamalar değişebilmektedir. Sonuç olarak, Z kuşağının yalnız seyahat sayesinde hem kendini gerçekleştirme imkânı bulduğu hem de zengin bir tatil deneyimi yaşadı̆̆ı görülmektedir. Öneri olarak, ileri de yapılacak çalışmalarda yalnız seyahat eden turistlerin seyahat motivasyonları kuşaklara göre farklılıkları karşılaştırmalı olarak 
incelenebilir. Bununla birlikte, değişen dünyada çalışma hayatına yakın zamanda başlamış olan ve turizm pazarında yeni bir segment oluşturan $Z$ kuşağı üzerine daha fazla çalışmaya gereksinim vardır. Destinasyon pazarlamasında $\mathrm{Z}$ kuşağının ilgi alanları doğrultusunda çekicilikler ön plana çıkarılmalıdır. 


\section{KAYNAKÇA}

Altunışık, R., Coşkun, R., Bayraktaroğlu, S. ve Yıldırım, E. (2010). Sosyal Bilimlerde Araştırma Yöntemleri SPSS Uygulamalı (6. Bask1). Sakarya: Sakarya Yayıncılık.

Aslantürk, E. ve Unur, K. (2019). Yalnız Seyahat Eden Kadınların Seyahat Deneyimleri. Seyahat ve Otel İşletmeciliği Dergisi, 16(3), 493-514.

Baltac1, A. (2019). Nitel Araştırma Süreci, Nitel Bir Araştırma Nasıl Yapılır?, Ahi Evran Üniversitesi Sosyal Bilimler Enstitüsü Dergisi (AEÜSBED), 5 (2): 368-388.

Besnili Memiş, O. (2019). “Kadınların İklim Değişikliği İle İlgili Algılarının Belirlenmesi”, Journal of Academic Value Studies, Vol:5, Issue:4; pp: 700-718 (ISSN:2149-8598).

Bianchi, C. (2016). Solo holiday travellers: Motivators and drivers of satisfaction and dissatisfaction. International Journal of Tourism Research, 18(2), 197-208. https://doi.org/10.1002/jtr.2049

Bond, M. (2015). Women Travel Statistics Explained by Travel Expert. Retrieved November, 14, 2015.

Brown, L. and H. Osman (2017). 'The Female Tourist Experience in Egypt as an Islamic Destination', Annals of Tourism Research 63: 12-22.

Brown, M. (2015). 'Visa Global Travel Intentions Study 2015'. Available at: https://pata.org/store/wpcontent/uploads/2015/09/Visa-GTI-2015-for_PATA.pdf (Erişim tarihi: 17.07.2020).

Chiang, C. Y. and Jogaratnam, G. (2006). Why Do Women Travel Solo for Purposes of Leisure?. Journal of Vacation Marketing, 12(1), 59-70.

Chung, J. Y., Baik, H. J., and Lee, C. K. (2017). The role of perceived behavioural control in the constraintnegotiation process: the case of solo travel. Leisure Studies, 36(4), 481-492.

Collins, K. M. T., Onwuegbuzie, A. J. and Jiao, Q. G. (2006). Prevalence of mixed-methods sampling designs in social science research. Evaluation \& Research in Education, 19 (2), 83-101.

Creswell, J. W. (2002). Educational Research: Planning, Conducting, and Evaluating Quantitative. Prentice Hall Upper Saddle River, NJ.

Crompton, J. L. (1979). 'An Assessment of the Image of Mexico as a Vacation Destination and the Influence of Geographical Location upon the Image', Journal of Travel Research, 18: 4, 18-23.

Crompton, J. L. and McKay, S.L. (1997). Motives of Visitors Attending Festival Events. Annals of Tourism Research, 24 (2), 425-439.

Dann, G. M. (1977). Anomie, Ego-Enhancement and Tourism. Annals of Tourism Research, 4(4), $184-194$.

El Gamil, R. (2018). The Tourist Experience of the Egyptian Solo Woman Traveler: An Exploratory Study. Journal of Tourism. Research, 93.

Esichaikul, R. (2012). Travel Motivations, Behavior and Requirements of European Senior Tourists to Thailand. Revista de Turismo y Patrimonio Cultural, Vol. 10 No 2. Special Issue. pp. 47-58.

Fodness, D. (1994). Measuring Tourist Motivation. Annals of Tourism Research: A. Social Sciences Journal, 21 (3), 555- 581.

Fridgen, J. D. (1996). Dimensions of Tourism, MI: Butterworth- Heinemann.

Frohlick, S. (2013). Sexuality, Women and Tourism: Cross-border Desires through Contemporary Travel. Oxon: Routledge.

Gnoth, J. (1997). Tourism Motivation and Expectation Formation Annals of Tourism Research: A Social Sciences Journal. Vol. 24, No. 2

Gomes, J. and Montenegro, M. (2016). Profile of Female Tourists Visiting Porto and North of Portugal. Worldwide Hospitality and Tourism Themes.

Google Trends (2020). https://trends.google.com/trends/?geo=TR (Erişim tarihi: 18.07.2020).

Haddouche, H. and Salomone, C. (2018). Generation Z and the tourist experience: tourist stories and use of social networks. Journal of Tourism Futures.

Haigh, R. (1995). Backpackers in Australia. Occasional paper no 20. Bureau of Tourism Research, Canberra.

Harman, S. (2014). Bağımsız Seyahat Eden Yerli Gezginlerin Seyahat Motivasyonları Üzerine Bir Araştırma. Uluslararası Yönetim İktisat ve İşletme Dergisi, 10(21): 107-128.

Hsu, C. H. and Huang, S. (2008). Travel Motivation: A Critical Review of the Concept's Development. Tourism Management: Analysis, Behaviour and Strategy: 14-27.

Hsu, C. H. and Sung, S. (1997) 'Travel Behaviors of International Students at a Midwestern University', Journal of Travel Research 36(1): 59-65.

Hyde, K. F. and Lawson, R. (2003). The Nature of Independent Travel. Journal of Travel Research, 42(1), 13-23.

Jordan, F. and H. Gibson (2005). “We're Not Stupid . . But We'll Not Stay Home Either”: Experiences of Solo Women Travelers', Tourism Review International 9(2): 195-211.

Kaba, G. ve Emekli, G. (2018). Turizmde Yükselen Eğilim: Yalnız Seyahat Eden Kadın Gezginler (Türkiye Örneği), Ege Coğrafya Dergisi, 27 (2): 111-126.

Karataş, İ. (2015). Sosyal Bilimlerde Nitel Araştırma Yöntemleri, Manevi Temelli Sosyal Hizmet Araştırmaları Dergisi, 1 (1): 62-80. 
Kim, J. H., Ritchie, J. R. B. and McCormick, B. (2012). Development of A Scale To Measure Memorable Tourism Experiences. Journal of Travel Research, 51(1), 12-25. Tourism Analysis, 15, 637-648.

Klook Association (2019). Travel Trends Report.( 2019). Hongkong. https://www.klook.com/, (Erişim tarihi: 20.07.2020).

Kuzu, A. (2013). Araştırmaların Planlanması, (Edt. Kurt, A., A.), Bilimsel Araştırma Yöntemleri (19-45), T.C. Anadolu Üniversitesi Yayını No: 2641.

Laesser, C., Beritelli, P. and Bieger, T. (2009), 'Solo Travel: Explorative Insights from a Mature Market (Switzerland)', Journal of Vacation Marketing, 15(3), pp.217-227.

Lin, K. M. (2006). “An Examination of the Relationship Between Experiential Marketing Strategy and Guests' Leisure Behavior in Taiwan Hot- Spring Hotels", Thesis For The Degree of Doctor of Sport Management United States Sports Academy.

Loker-Murphy, L. and Pearce, P. L. (1995). Young Budget Travelers: Backpackers in Australia. Annals of Tourism Research, 22(4), 819-843.

Lubbe, B. (1998). Primary Image as a Dimension of Destination Image: An Empirical Assessment. Journal of Travel and Tourism Marketing, 7(4), 21-43. 14.

Makatouni, A. (2002). What motivates consumers to buy organic food in the UK? Results from a qualitative study. British Food Journal, 104(3/4/5): 345-352.

Mansfield, Y. (1992). From Motivation to Actual Travel. Annals of Tourism Research, 19: 399-419. Maslow, A. 1943.A Theory of Human Motivation.

McCrindle, M. (2014). The ABC of XYZ: Understanding the Global Generations. The ABC of XYZ: Understanding the Global Generations.

McIntosh, R. W. and Goeldner, C. R. (1990). Tourism Principles, Practices, Philosophy (6th edition), New York, John Wiley.

McNamara, K. E. and Prideaux, B. (2010). A typology of solo independent women travellers. International Journal of Tourism Research, 12(3), 253-264. https://doi.org/10.1002/jtr.751

Mehmetoğlu, M., Dann, G. M. and Larsen, S. (2001). Solitary Travellers in the Norwegian Lofoten Islands: Why Do People Travel On Their Own?. Scandinavian Journal of Hospitality and Tourism, 1(1), 19-37.

Middleton, V. and Clarke, J. (2001). Marketing in Travel and Tourism, Roshester, Kent.

Mignon, J. M. (2003). "Le tourisme des jeunes. Une valeur sûre", dans Cahier Espaces, No. 77.

Mill, R. C. and Morrison, A. M. (2009). The tourism system (6th ed.). Dubuque, IA: Kendall/Hunt.

Moutinho, L. (2000). Trends in Tourism. Strategic Management in Tourism, 3-16.

Murphy, L. (2001). Exploring Social Interactions of Backpackers. Annals of Tourism Research, 28(1), 50-67.

Murphy, P. (1985). Tourism: A Community Approach, Metheun Inc., London.

Noy, C. (2004). “The Trip Really Changed Me: Backpackers' Narrative of Self-Change.” Annals of Tourism Research, 31 (1): 78-102.

Onwuegbuzie, A. J. and Leech, N. L. (2007). A Call for qualitative power analyses. Quality \& Quantity, 41, 105121.

Osman, H., Brown, L. and Phung, T. M. T. (2020). The Travel Motivations and Experiences of Female Vietnamese Solo Travellers. Tourist Studies, 20(2), 248-267.

Pearce, P. L. (1982). Perceived Changes in Holiday Destinations. Annals of Tourism Research, 9(2), 145-164.

Pereira, A. and Silva, C. (2018). Motivations and Experiences of Women Solo Travellers. International Journal of Multidisciplinarity in Business and Science, 4(5), 134-138.

Phocus Wire, (2020). https://www.phocuswire.com/home-sharing-second-story (erişim tarihi: 11.06.2020).

Pine, B. J. and Gilmore, J. H. (1998). Welcome to the Experience Economy. Harvard Business Review, 76(4), 97-105.

Pizam, A., Neumann, Y. and Reichel, A. (1979). Tourist Satisfaction: Uses and Misuses. Annals of Tourism Research, 6(2), 195-197.

Prayag, G. and Ryan, C. (2011). The Relationship Between the 'Push' and 'Pull' factors of a Tourist Destination: The Role of Nationality-An Analytical Qualitative Research Approach. Current Issues in Tourism, 14(2), 121-143.

Riley, P. (1988). Road Culture of International Long-Term Budget Travellers. Annals of Tourism Research 15, 313-28.

Robinson, V. M. and Schänzel, H. A. (2019). A tourism inflex: Generation Z travel experiences. Journal of Tourism Futures.

Scheyvens, R. (2002). Backpacker Tourism and Third World Development, Annals of Tourism Research, 29(1), 144-164.

Smith, V. L. (Ed.). (1977). Hosts and Guests: The Anthropology of Tourism, Philadelphia, PA: University of Pennsylvania Press. 
Song, H. J., Lee, C. K., Park, J. A., Hwang, Y. H. and Reisinger, Y. (2015). The Influence of Tourist Experience on Perceived Value and Satisfaction with Temple Stays: The Experience Economy Theory. Journal of Travel and Tourism Marketing, 32(4), 401-415.

Şencan, H. (2005). Sosyal ve Davranışsal Ölçümlerde Güvenirlik ve Geçerlilik. Ankara: Seçkin Yayıncılık.

Tulgan, B. (2013). "Meet Generation Z: the second generation within the giant 'Millennial' cohort", Rainmaker Thinking, available at: http://rainmakerthinking.com/assets/uploads/2013/10/Gen-Z-Whitepaper.pdf (Erişim tarihi: 16.07.2020).

Tükenmez, E. G. (2019). Türkiye'de Yalnız Seyahat Eden Kadınlar: Deneyimleri, Tercihleri, Motivasyon ve Kısıtları, Yüksek Lisans Tezi, Dokuz Eylül Üniversitesi Sosyal Bilimler Enstitüsü.

Wilson, E. C. (2004). A 'Journey of Her Own'. The Impact of Constraints on Women's Solo Travel. PhD's Thesis submitted to the Griffith University, Australia.

Yang, E. C. L. (2020). What motivates and hinders people from travelling alone? A study of solo and non-solo travellers. Current Issues in Tourism, 1-14.

Yang, R. and Tung, V. W. S. (2018). How does family influence the travel constraints of solo travelers? Construct specification and scale development. Journal of Travel \& Tourism Marketing, 35(4), 507516.

Yıldırım, A. ve Şimşek, H. (2016). Sosyal Bilimlerde Nitel Araştırma Yöntemleri, Ankara, Seçkin Yayıncılık. Yıldırım, A. ve Şimşek, H. (2008). Sosyal Bilimlerde Nitel Araştırma Yöntemleri (6. Baskı). Ankara: Seçkin Yayıncilik. 